\title{
Pathological analysis of extracapsular extension of metastatic lymph node and its potential impact on nodal clinical target volume in the radiotherapy of esophageal squamous cell carcinoma
}

\author{
Z. W. WANG ${ }^{1,2, *}$, W. ZHANG ${ }^{1,2, *}$, W. DONG ${ }^{1,2}$, B. S. $\mathrm{LI}^{2, *}$, D. B. $\mathrm{MU}^{3}$, W. HUANG ${ }^{2}$, J. ZHANG ${ }^{2}$, H. S. LI' ${ }^{2}$, Z. C. ZHANG ${ }^{2}$, H. Q. LIN ${ }^{2}$, Y. YI \\ ${ }^{1}$ Department of Radiation Oncology, Cancer Hospital, Tianjin Medical University, Tianjin, P.R.China; ${ }^{2}$ Department of Radiation Oncology, \\ Shandong Cancer Hospital, Shandong Academy of Medical Sciences, Jinan, P.R.China; ${ }^{3}$ Department of Pathology, Shandong Cancer Hospital, \\ Shandong Academy of Medical Sciences, Jinan, P.R.China \\ ${ }^{*}$ Correspondence: baoshli@yahoo.com \\ ${ }^{\ddagger}$ Contributed equally to this work.
}

Received August 26, 2013 / Accepted October 3, 2013

\begin{abstract}
There is no consensus regarding the clinical target volume (CTV) margins which surround the gross tumor volume of metastatic lymph nodes (LN) in radiotherapy of esophageal squamous cell carcinoma (ESCC). This study retrospectively assessed the distance of extracapsular extension (ECE) of metastatic LN in thoracic ESCC and defined nodal CTV margins. Histological sections of metastatic LNs from 217 patients with thoracic ESCC were re-examined. The incidence and maximal distance of ECE of metastatic LNs were assessed. The relationships between ECE and clinicopathologic features were also investigated. The ECE was found in $37.3 \%$ of patients $(81 / 217)$ and $23.1 \%$ of metastatic LN (159/689), and the incidences had a significant relationship with $\mathrm{N}$ stage and LN size. The median distance of ECE was $1.0 \mathrm{~mm}$ (range, 0.2-9.7 mm). The distance of ECE showed a positive correlation with LN size (Spearman's correlation coefficient $=0.419 ; p<0.001$ ). The ECE distances of LN with $<10 \mathrm{~mm}$ diameter were significantly smaller than LN with $10-30 \mathrm{~mm}$ diameter $(p<0.001)$. The $95^{\text {th }}$ percentiles of ECE distances for these two groups were $3 \mathrm{~mm}$ and $5 \mathrm{~mm}$, respectively. For pathologic $\mathrm{LN}<10 \mathrm{~mm}$ in diameter, a 3-mm CTV margin appears to be adequate to encompass $95 \%$ of the microscopic ECE, and for LN 10-30 mm, a 5-mm CTV margin is recommended.
\end{abstract}

Key words: esophageal squamous cell carcinoma, radiotherapy, clinical target volume, extracapsular extension, lymph node

Esophageal cancer is a highly aggressive malignancy with a poor prognosis. Worldwide, it is the sixth most common cancer and fifth most common cause of cancer deaths in males, and in females it rank as the eleventh most common cancer and eighth most common cause of cancer deaths [1,2]. In China, esophageal cancer was the fifth and sixth most common cancer in males and females, respectively, and the majority of cases are esophageal squamous cell carcinoma (ESCC) with a high proportion of patients diagnosed with locally advanced disease $[3,4]$. The current preferred treatment for locally advanced ESCC is either neoadjuvant chemoradiotherapy followed by surgery, or concurrent chemoradiotherapy alone $[5,6]$. Obviously, Radiotherapy plays an important role in the treatment of locally advanced ESCC. However, local failure still occurs in more than $50 \%$ of the patients when definitive concurrent chemoradiotherapy is given [7-9].
With the development of radiotherapy, three-dimensional conformal and intensity-modulated radiotherapy have been routinely used in clinical practice. These new technologies could accurately deliver radiation to shaped target areas and increase the radiation dose to the tumor while reducing radiation exposure to the normal organs at risk [10-12]. The superiority of new technologies in radiotherapy may generate promising treatment effects. However, the superiority depends on the accurate delineation of the target volume.

Unfortunately, there are still many controversies regarding target delineation for ESCC. Previous studies about nodal clinical target volume (CTVn) were often concerned about whether CTVn should encompass the areas at risk for nodal metastases and which areas were at risk. However, few studies were concerned about another important issue: what margins of CTVn should be added to the gross tumor volume (GTV) 
of nodal disease. Up to now, no consensus has been reached on this question. Different institutions have different CTVn standards which range from $0 \mathrm{~mm}$ to $15 \mathrm{~mm}[8,13-16]$. Unfortunately, these standards are empirically developed without pathological evidence to support them and may be excessive or insufficient.

Microscopic extracapsular extension (ECE) in metastatic lymph nodes (LN) is an important factor that should be taken into account in the delineation of CTVn in ESCC. Several studies have reported that ECE of ESCC is associated with recurrence and poor prognosis [17-19]. Because the optimal CTVn can ensure adequate radiation dose to the areas at a high risk for ECE and may improve the local control rate and prognosis, it is necessary to define the appropriate CTVn margins based on pathological evidence. Several investigators have previously measured the extent of ECE of metastatic LNs in patients with non small cell lung cancer (NSCLC) and head and neck squamous cell carcinoma (HNSCC), respectively [20-22]. However, to our knowledge, no previous studies reported the extent of ECE in metastatic LN of ESCC. In the study, we want to determine optimal CTVn margins in radiotherapy through measuring the distance of ECE beyond the capsule of metastatic LN in thoracic ESCC.

\section{Patients and methods}

Specimen selection. A retrospective search in the pathology database of our institution was conducted for patients with thoracic ESCC who had at least one metastatic LN. All patients received transthoracic esophagectomy with extensive lymphadenectomy, using either two-field or three-field approach between January 2011 and December 2012. Patients were excluded if they had received preoperative cancer therapy. A total of 248 patients were identified in the initial screening.

The histological sections of metastatic LN from 246 patients except for 2 patients whose specimens were not available were re-examined for ECE status and the ECE-positive LN were measured for the distance of ECE. All pathological analysis for

Table 1. Clinicopathological characteristics of patients and ECE incidence

\begin{tabular}{|c|c|c|c|c|}
\hline \multirow[b]{2}{*}{ Features } & \multicolumn{3}{|c|}{ Patients } & \multirow[b]{2}{*}{$P$ values } \\
\hline & $\begin{array}{c}\text { ECE negative } \\
(n)\end{array}$ & $\begin{array}{c}\text { ECE positive } \\
(n)\end{array}$ & $\begin{array}{c}\text { ECE incidence } \\
(\%)\end{array}$ & \\
\hline Sex & & & & 0.882 \\
\hline Male & 108 & 65 & 37.6 & \\
\hline Female & 28 & 16 & 36.4 & \\
\hline Primary tumor site & & & & 0.149 \\
\hline Upper esophagus & 9 & 4 & 30.8 & \\
\hline Middle esophagus & 89 & 44 & 33.1 & \\
\hline Lower esophagus & 38 & 33 & 46.5 & \\
\hline Primary tumor stage & & & & 0.508 \\
\hline $\mathrm{T} 1$ & 8 & 2 & 20.0 & \\
\hline $\mathrm{T} 2$ & 21 & 10 & 32.3 & \\
\hline T3 & 88 & 54 & 38.0 & \\
\hline $\mathrm{T} 4$ & 19 & 15 & 44.1 & \\
\hline Nodal stage & & & & $<0.001$ \\
\hline N1 & 100 & 32 & 24.2 & \\
\hline N2 & 29 & 28 & 49.1 & \\
\hline N3 & 7 & 21 & 75.0 & \\
\hline Disease stage & & & & $<0.001$ \\
\hline IIB & 27 & 10 & 27.0 & \\
\hline IIIA & 64 & 20 & 23.8 & \\
\hline IIIB & 23 & 21 & 47.7 & \\
\hline IIIC & 22 & 30 & 57.7 & \\
\hline Length of Tumor & & & & 0.252 \\
\hline$\leq 4 \mathrm{~cm}$ & 68 & 34 & 33.3 & \\
\hline$>4 \mathrm{~cm}$ & 68 & 47 & 40.9 & \\
\hline Tumor differentiation & & & & 0.301 \\
\hline Well & 28 & 10 & 26.3 & \\
\hline Moderate & 66 & 44 & 40.0 & \\
\hline poor & 42 & 27 & 39.1 & \\
\hline
\end{tabular}

Abbreviations: ECE, extracapsular extension. 
ECE was performed by the single pathologist (D.M.) with 20 years of experience. Lymph node specimens would be excluded from this study if the normal architecture of the LN could not be recognized or LN specimens were not intact. The LN specimens with diameter larger than $3 \mathrm{~cm}$ were also excluded, because the space of slide was limited to show the full range of ECE. Twenty-nine out of 246 patients were excluded from the study based on the criterion above.

Patient characteristics. The general characteristics of 217 patients (male 173, female 44) with thoracic ESCC identified in the initial analysis are listed in Table 1. The median age was 59 years ranging from 37 to 85 years. Concerning the location of primary tumors, 204 (94\%) of the patients were recorded as the middle or lower thoracic ESCC and only 13 (6\%) the upper thoracic ESCC. Tumor stage was classified according to the American Joint Committee on Cancer 2010 guidelines [23]. There were $10(4.6 \%)$ patients with T1 stage, $31(14.3 \%)$ with T2 stage, $142(68.6 \%)$ with T3 stage and $34(15.7 \%)$ with T4 stage. The distribution of N stage was: $132(60.8 \%)$ patients with N1 stage, 57 (26.3\%) with N2 stage, and 28 (12.9\%) with N3 stage.

ECE measurement. According to the similar studies previously reported [20,24], ECE was defined as microscopic cancer cells spreading to extranodal connective tissues including microscopic extension of tumor cells through the capsule of LN into the extranodal tissues, deposits of metastatic cancer cells and tumor emboli cancer cell in fibrofatty tissue surrounding nodes. These could be recognized by tumor cells outside the capsule which were sometimes accompanied by tumor reaction including desmoplastic response and giant cell reaction to extracellular keratin. The specimens of ECE positive LNs were measured for the distance of ECE by a micrometer. The distance of ECE was defined as the distance from the LN capsule to the furthest identified tumor cells. In cases in which the capsule partly disappeared because of tumor invasion, the distance was measured from a capsular equivalent which was extrapolated from the nearest normal portion of the capsule. The pathologic features of each metastatic LN including the largest axial diameter and location were also recorded. Fig. 1 shows the examples of three kinds of microscopic ECE in metastatic LNs.

Statistical analysis. The normality of quantitative variables was assessed on residuals with Shapiro-Wilks test. The impact of clinical parameters of patients and LNs on incidence of ECE was assessed using the chi-square test. Multiple step-wise logistic regression analysis was used to examine the independent relationship between the incidence of ECE and these clinical parameters. The Student $t$ test was applied to compare the mean axial diameter of LNs with and without ECE. For the distances of ECE were highly skewed and could not be transformed to normality, the differences between groups of ECE distance were analyzed by the Mann-Whitney $U$ test or the Kruskal-Wallis test followed by the Mann-Whitney U test. A bonferroni correction was applied to correct for multiple comparisons of the distances of ECE. Spearman's rank correlation was performed to evaluate the relationship between the distance of ECE and LN size. A $p$ value of less than 0.05 on two-sided tests was set as the threshold of significance. The statistical analyses were performed using SPSS version 16.0 (SPSS Inc, Chicago, USA).

\section{Results}

Clinicopathological characteristics of patients and ECE incidence. As shown in Table 1, 37.3\% of patients (81/217) exhibited the evidence of ECE. ECE incidence showed significant associations with nodal stage $(p<0.001)$ and disease stage $(P<0.001)$ in all patients. Step-wise logistic regression analysis identified only $\mathrm{N}$ stage as the independent influence factor ( $p<0.001 ;$ OR=3.049; 95\% confidence interval: 1.994-4.662). The incidences of ECE stratified by N stage were $24.2 \%$ $(32 / 132)$ in $\mathrm{N} 1,49.1 \%(28 / 57)$ in $\mathrm{N} 2$, and $75 \%(21 / 28)$ in N3. However, ECE incidence was not found to be associated with the other clinicopathological factors.

Characteristics of metastatic LN and ECE incidence. A total of 3,792 nodes were removed from 217 patients, with a mean of 17.5 nodes per patient. The ratio of positive lymph
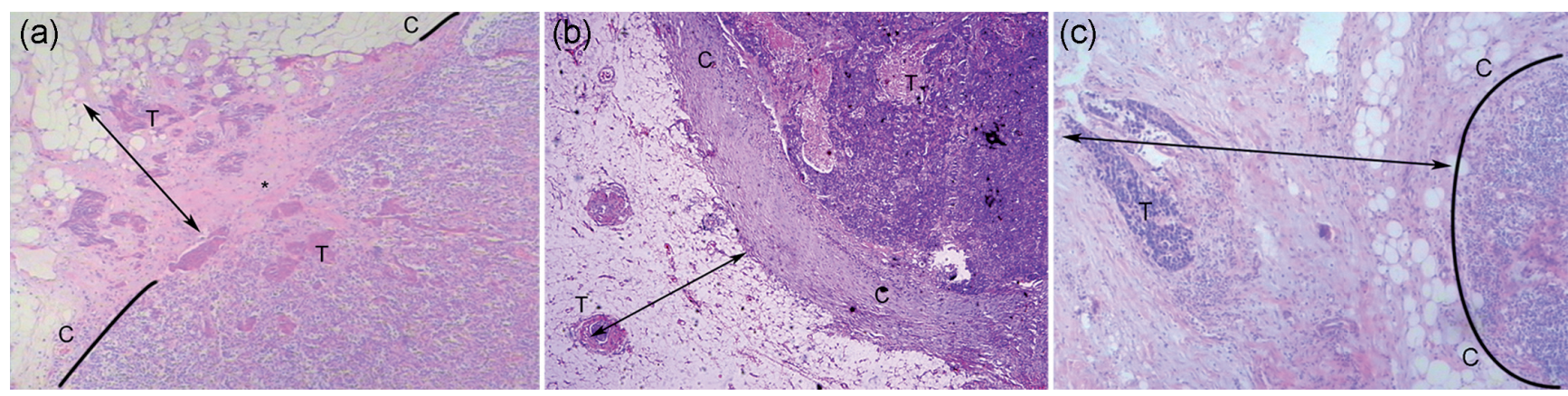

Figure 1. Histological specimens (hematoxylin-eosin staining, $\times 40)$ demonstrating three kinds of extracapsular extension of esophageal squamous cell cancer. Microscopic extension of tumor cells through the capsule of lymph nodes into the extranodal tissues (a), tumor emboli cancer cell (b) and deposits of metastatic cancer cells (c) in fibrofatty tissue surrounding nodes. Capsule of lymph nodes was denoted by $\mathrm{C}$, tumor was denoted by $\mathrm{T}$, the site where the tumor ruptured the capsule is denoted by an asterisk and the measured distance was marked by straight line. 
node to all lymph nodes resected was $18.2 \%$ (689/3792). The characteristics of the metastatic LNs and incidence of ECE are listed in Table 2. ECE was detected in $23.1 \%$ (159/689). The mean axial diameter for $\mathrm{LN}$ with ECE was $14.0 \mathrm{~mm}$, while the mean axial diameter for $\mathrm{LN}$ without ECE was $11.9 \mathrm{~mm}$. The diameters of nodes with and without ECE were significantly different $(p<0.001)$. When the metastatic LN were divided into three groups by size $(<10 \mathrm{~mm}, 10-19 \mathrm{~mm}, 20-30 \mathrm{~mm})$, the ECE incidences were $15.7 \%$ (36/230), 25.1\% (97/386) and $35.6 \%(26 / 73)$, respectively $(p<0.001)$. In addition, the ECE incidence also correlated significantly with the number of nodes involved $(p=0.047)$ and disease stage $(p=0.027)$. However, step-wise logistic regression analysis identified only lymph node size $(p<0.001 ; O R=1.808 ; 95 \%$ confidence interval: $1.352-2.420)$ and $\mathrm{N}$ stage $(p=0.006 ; O R=1.377$; 95\% confidence interval: $1.094-1.733$ ) as the independent influence factor.

Table 2. Characteristics of metastatic lymph nodes and ECE incidence

\begin{tabular}{|c|c|c|c|}
\hline Group & $\begin{array}{l}\text { Specimens } \\
(n)\end{array}$ & $\begin{array}{c}\text { ECE incidence } \\
n(\%)\end{array}$ & $P$ value \\
\hline Sex & & & 0.956 \\
\hline Male & 571 & $132(23.1)$ & \\
\hline Female & 118 & $27(22.9)$ & \\
\hline Lymph node size & & & 0.001 \\
\hline$<10 \mathrm{~mm}$ & 230 & $36(15.7)$ & \\
\hline $10-19 \mathrm{~mm}$ & 386 & $97(25.1)$ & \\
\hline $20-30 \mathrm{~mm}$ & 73 & $26(35.6)$ & \\
\hline Nodal location & & & 0.558 \\
\hline Cervical & 43 & $14(32.6)$ & \\
\hline Upper thoracic & 39 & $8(20.5)$ & \\
\hline Middle thoracic & 232 & $50(21.6)$ & \\
\hline Lower thoracic & 100 & $21(21.0)$ & \\
\hline Abdominal & 275 & $66(24.0)$ & \\
\hline Primary tumor stage & & & 0.493 \\
\hline $\mathrm{T} 1$ & 13 & $2(15.4)$ & \\
\hline $\mathrm{T} 2$ & 83 & $24(28.9)$ & \\
\hline T3 & 429 & $94(21.9)$ & \\
\hline $\mathrm{T} 4$ & 164 & $39(23.8)$ & \\
\hline Nodal stage & & & 0.047 \\
\hline N1 & 183 & $34(18.6)$ & \\
\hline N2 & 233 & $49(21.0)$ & \\
\hline $\mathrm{N} 3$ & 273 & $76(27.8)$ & \\
\hline Disease stage & & & 0.027 \\
\hline IIB & 49 & $12(24.5)$ & \\
\hline IIIA & 123 & $19(15.4)$ & \\
\hline IIIB & 175 & $34(19.4)$ & \\
\hline IIIC & 342 & $94(27.5)$ & \\
\hline Tumor differentiation & & & 0.930 \\
\hline Well & 75 & $16(21.3)$ & \\
\hline Moderate & 347 & $81(23.3)$ & \\
\hline poor & 267 & $62(23.2)$ & \\
\hline
\end{tabular}

Abbreviation as in Table 1.

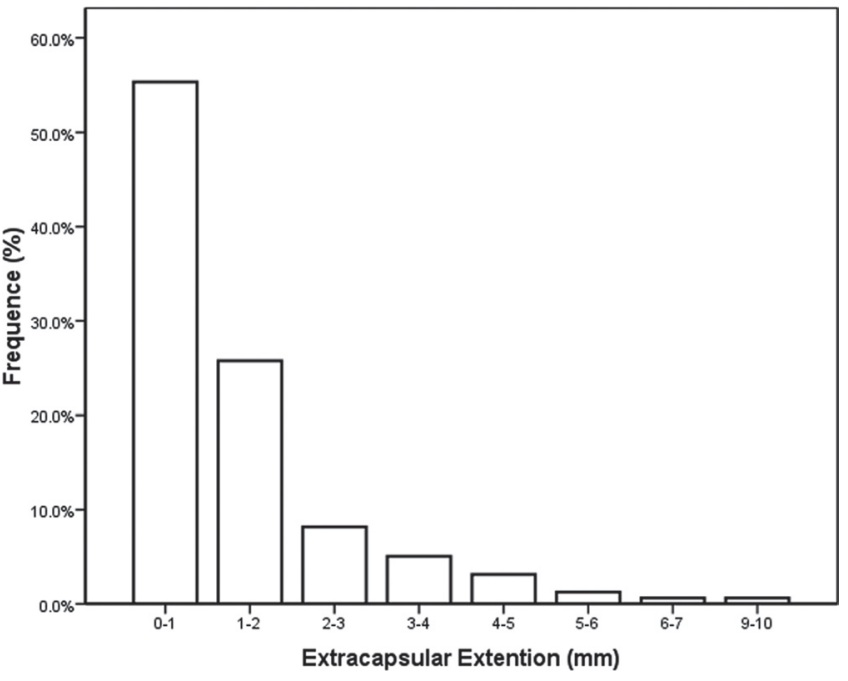

Figure 2. Distributions of the extracapsular extension distance.

Distance of ECE. The mean and median distances of ECE were $1.4 \mathrm{~mm}$ and $1.0 \mathrm{~mm}$, respectively, with the range from $0.2 \mathrm{~mm}$ to $9.7 \mathrm{~mm}$. Among the LN with ECE, $81.1 \%(129 / 159)$ had ECE $\leq 2 \mathrm{~mm}, 89.3 \%(142 / 159) \leq 3 \mathrm{~mm}, 94.3 \%(150 / 159)$ $\leq 4 \mathrm{~mm}, 97.5 \%(155 / 159) \leq 5 \mathrm{~mm}$. Histogram distributions (Fig. 2) showed a positively skewed, leptokurtic distribution of ECE (skewness 2.548, kurtosis 8.992). Among the 38 LNs with $\mathrm{ECE} \geq 2 \mathrm{~mm}$, there were only three $\mathrm{LNs}<10 \mathrm{~mm}$ in diameter. The specimens of these nodes were examined again, but no special pathologic feature was found.

Relationship between distance of ECE and clinicopathological parameters of LN. As shown in the scatter plot of distance of ECE versus LN size for all 159 individual LNs (Fig. 3), there was a positive correlation between distance of

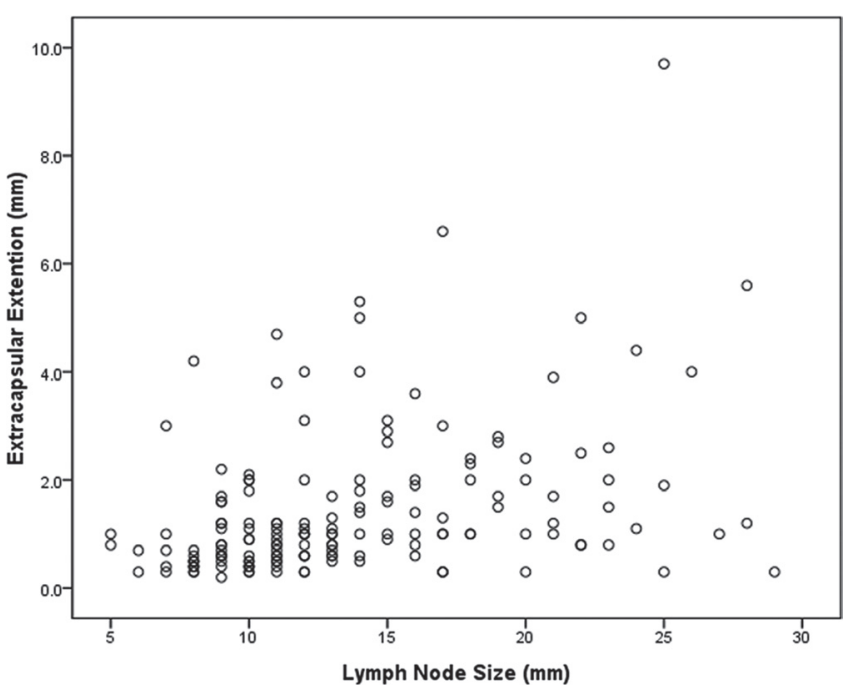

Figure 3. Scatter plot of distribution of extracapsular extension (ECE) distance versus lymph node size for all 159 ECE-positive lymph nodes. 
ECE and LN size (Spearman's correlation coefficient $=0.419$; $p<0.001)$. There were significant differences among the three groups of $\mathrm{LN}(<10 \mathrm{~mm}, 10-19 \mathrm{~mm}, 20-30 \mathrm{~mm}, p<0.001)$. In the subgroup analysis through bonferroni correction, there were differences between the subgroups $<10 \mathrm{~mm}$ and $10-19 \mathrm{~mm}$, but the differences between $10-19 \mathrm{~mm}$ and $20-30 \mathrm{~mm}$ vanished $(<10 \mathrm{~mm}$ vs $10-19 \mathrm{~mm}, p=0.002 ; 10-19 \mathrm{~mm}$ vs $20-30 \mathrm{~mm}$, $p=0.048$; corrected $p=0.017$ ). Based on the above results, the LNs were divided into two groups $(<10 \mathrm{~mm}, 10-30 \mathrm{~mm})$ and the differences between them were significant $(p<0.001)$. The $95^{\text {th }}$ percentile of ECE distances for these two groups was 3 $\mathrm{mm}$ and $5 \mathrm{~mm}$, respectively. The other clinicopathological parameters, such as age, gender, nodal location, nodal stage, tumor stage and differentiation, were not associated with the distance of ECE (Table 3).

\section{Discussion}

The purpose of the study was to clarify CTVn margins in ESCC through a retrospective pathological analysis of microscopic extracapsular extension of metastatic LNs. The incidence of ECE had a significant relationship with $\mathrm{N}$ stage and diameter of LNs. The distance of ECE was correlated to the diameter of LNs. The median distance of ECE was $1.0 \mathrm{~mm}$ with a range from $0.2 \mathrm{~mm}$ to $9.7 \mathrm{~mm}$. The ECE distances of LNs with $<10 \mathrm{~mm}$ diameter were smaller than LNs with a diameter of $10-30 \mathrm{~mm}$. The $95^{\text {th }}$ percentile of ECE distances for these two groups was $3 \mathrm{~mm}$ and $5 \mathrm{~mm}$, respectively. Our results suggest $3-\mathrm{mm}$ and 5-mm CTVn margins around nodal GTV to encompass $95 \%$ of the microscopic ECE of metastatic LN $<10 \mathrm{~mm}$ and $10-30 \mathrm{~mm}$ in size, respectively.

Unlike the similar studies about the CTVn of HNSCC and NSCLC [20-22], we not only assessed the microscopic extension of tumor cells through the capsule of LN into the extranodal tissues, but also assessed the tumor deposits and emboli cancer cells emboli in fibrofatty tissue surrounding nodes. This was because in an earlier study about ESCC, Baba $M$ et al. [24] reported the perinodal tissue tumor involvement which we called ECE was composed of these three kinds of subclinical lesions as mentioned above. The similar phenom-

Table 3 Relationship between distance of ECE and clinicopathological parameters

\begin{tabular}{|c|c|c|c|}
\hline Group & $\begin{array}{c}\text { No. of } \\
\text { Lymph node (\%) }\end{array}$ & $\begin{array}{l}\text { Median ECE extent }(\mathrm{mm}) \\
\text { (Interquartile range) }\end{array}$ & $P$ value \\
\hline Total LN ( $\mathrm{n}=159)$ & $159(100)$ & $1.0(0.6-1.9)$ & \\
\hline Lymph node size & & & $<0.001$ \\
\hline$<10 \mathrm{~mm}$ & $36(20.8)$ & $0.6(0.4-1.0)$ & \\
\hline $10-19 \mathrm{~mm}$ & $97(62.7)$ & $1.0(0.6-1.8)$ & \\
\hline $20-30 \mathrm{~mm}$ & $26(16.5)$ & $1.7(1.0-3.1)$ & \\
\hline Nodal location & & & 0.250 \\
\hline Cervical & $14(8.8)$ & $1.0(0.5-2.1)$ & \\
\hline Upper thoracic & $8(5.0)$ & $0.8(0.5-1.0)$ & \\
\hline Middle thoracic & $50(31.4)$ & $1.2(0.6-2.0)$ & \\
\hline Lower thoracic & $21(13.2)$ & $0.8(0.6-1.2)$ & \\
\hline Abdominal & $66(41.5)$ & $1.0(0.6-2.0)$ & \\
\hline Differentiation & & & 0.543 \\
\hline Well & $16(10.1)$ & $1.1(0.4-1.9)$ & \\
\hline Moderate & $81(51.0)$ & $1.0(0.6-2.0)$ & \\
\hline Poor & $62(39.0)$ & $1.0(0.5-1.7)$ & \\
\hline Sex & & & 0.197 \\
\hline Male & $141(88.7)$ & $1.0(0.6-1.7)$ & \\
\hline Female & $18(11.3)$ & $1.2(0.7-2.9)$ & \\
\hline Age & & & 0.636 \\
\hline$<60$ & $71(44.7)$ & $1.0(0.6-1.8)$ & \\
\hline$\geq 60$ & $88(55.3)$ & $1.0(0.6-2.0)$ & \\
\hline Primary tumor stage & & & 0.379 \\
\hline $\mathrm{T} 1,2$ & $26(16.4)$ & $1.0(0.5-1.6)$ & \\
\hline $\mathrm{T} 3$ & $94(59.1)$ & $1.0(0.6-2.0)$ & \\
\hline $\mathrm{T} 4$ & $39(24.5)$ & $0.8(0.5-1.4)$ & \\
\hline Nodal stage & & & 0.277 \\
\hline N1 & $34(21.4)$ & $1.2(0.8-2.0)$ & \\
\hline $\mathrm{N} 2$ & $49(30.8)$ & $1.0(0.5-2.0)$ & \\
\hline N3 & $76(47.8)$ & $1.0(0.6-1.5)$ & \\
\hline
\end{tabular}

Abbreviation as in Table 1. 
enon was also observed also by some other investigators [25]. Although the mechanism of their formation has not been elucidated, it is obvious that the three kinds of subclinical disease represent the characteristics of metastatic LNs and the CTVn should cover all of them.

Baba $\mathrm{M}$ et al. [24] found the incidences of ECE were 43.3\% in node-positive patients with ESCC and 22.2\% in metastatic LN. Sakai M et al. [17] and Metzger et al. [19] reported the incidences of ECE were $41.2 \%$ and $35 \%$ in node-positive patients respectively and Sakai M, et al. [17] also showed a $24.5 \%$ incidence of ECE in metastatic LN. In our study the ECE incidences were $37.3 \%$ and $23.1 \%$, respectively. It appears that our results are generally consistent with the previous studies in ESCC. In the present study, we found the incidence of ECE increased with N stage. The studies of ECE in ESCC mentioned above described the similar results $[17,19,24,25]$. However, the same phenomenon wasn't observed in HNSCC and NSCLC [20-22]. Thus, it may reflect a special biological behavior of ESCC.

It seems reasonable that $\mathrm{ECE}$ of metastatic $\mathrm{LNs}$ in advanced $\mathrm{N}$ stage have the ability to spread farther than those in early one. However, we failed to find a correlation between the distance of ECE and node stage. Yuan et al. have reported that poor differentiation of NSCLC may be significantly associated with farther ECE distance [21]. Similar results were not obtained in the studies about ECE in ESCC including ours. This may also reflect that there are different biological characteristics between ESCC and NSCLC.

Several authors have previously shown that the incidence of ECE in metastatic LN of HNSCC and NSCLC is positively correlated with LN size $[21,22]$. Similar results are obtained in our study about ECE. Further more, our study demonstrated that there was a correlation between the distance of ECE and LN size. ECE of larger LNs extended farther than the smaller ones. These are consistent with the studies by Yuan et al. and Ghadjar et al [21,22]. However, Apisarnthanarax et al. failed to demonstrate a correlation between the extent of ECE and LN size of HNSCC [20]. Thus, besides LN size, other biological mechanisms probably contribute to more aggressive growth.

There are several potential limitations in our study. Firstly, among the LNs assessed, there were only 74 metastatic LN $>20 \mathrm{~mm}$ and no $\mathrm{LN}>30 \mathrm{~mm}$ in diameter was included in this study. The primary reason was that patients with bigger LNs were diagnosed as advanced stage and lost opportunity for surgery. The other reason was that the specimens of larger LN especially more than $30 \mathrm{~mm}$ in diameter were often disrupted and could not be measured. Thus, the incidence and distance of ECE of bigger LNs need to be further studied in a prospective way. Secondly, the pathological slices assessed in this retrospective study were the largest cross-sections of $\mathrm{LN}$, but these could not demonstrate the ECE in every directions. Further more, the extent of tissue shrinkage due to fixation is hardly to be obtained retrospectively. So the incidence and distance of ECE could be somewhat underestimated. The third limitation is the relationships of the pathologic findings and preoperative computed tomography (CT) images have not been investigated. A minority of bigger lesions of ECE may be visible on CT images. For these situations, the CTVn margins based on pathological finding may be somewhat overestimated. But because the study was retrospective, it was hardly to get a one-to-one correspondence between the pathological cross-section of LN and its CT image.

To overcome these limitations, we will carry out a prospective study with the following characteristics: 1 . Implementing entirely whole-mount sections of LNs to obtain more accurate pathologic data. 2. Collecting all the CT images of the LNs to get accurately one-to-one correspondence between the pathological cross-section of LN and its CT image. 3. Calculating the tissue shrinkage ratio. 4. Expanding the sample size of larger LNs.

In conclusion, the incidence of ECE had a positively relationship with $\mathrm{N}$ stage and diameter of $\mathrm{LN}$ and the extent of ECE was positively correlated to the diameter of LN. According to the pathologic results of our ECE investigations, we suggest 3-mm and 5-mm CTVn margins should be added to the nodal GTV for LN $<10 \mathrm{~mm}$ and $10-30 \mathrm{~mm}$ of ESCC treated with radiotherapy, respectively.

\section{References}

[1] JEMAL A, BRAY F, CENTER MM, FERLAY J, WARD E, et al. Global cancer statistics. CA Cancer J Clin 2011; 61: 69-90. http://dx.doi.org/10.3322/caac. 20107

[2] FERLAY J, SHIN HR, BRAY F, FORMAN D, MATHERS C, et al. Estimates of worldwide burden of cancer in 2008: GLOBOCAN 2008. Int J Cancer 2010; 127: 2893-2917. http://dx.doi. org/10.1002/ijc.25516

[3] CHEN W, HE Y, ZHENG R, ZHANG S, ZENG H, et al. Esophageal cancer incidence and mortality in China, 2009. J Thorac Dis 2013; 5: 19-26.

[4] CHENG J, KONG L, HUANG W, LI B, LI H, et al. Explore the radiotherapeutic clinical target volume delineation for thoracic esophageal squamous cell carcinoma from the pattern of lymphatic metastases. J Thorac Oncol 2013; 8: 359-365.

[5] HERSKOVIC A, RUSSELL W, LIPTAY M, FIDLER MJ AlSarraf M. Esophageal carcinoma advances in treatment results for locally advanced disease: review. Ann Oncol 2012; 23: 1095-1103. http://dx.doi.org/10.1093/annonc/mdr433

[6] PENNATHUR A, GIBSON MK, JOBE BA LUKETICH JD. Oesophageal carcinoma. Lancet 2013; 381: 400-412. http:// dx.doi.org/10.1016/S0140-6736(12)60643-6

[7] COOPER JS, GUO MD, HERSKOVIC A, MACDONALD JS, MARTENSON JA, Jr., et al. Chemoradiotherapy of locally advanced esophageal cancer: long-term follow-up of a prospective randomized trial (RTOG 85-01). Radiation Therapy Oncology Group. JAMA 1999; 281: 1623-1627. http://dx.doi. org/10.1001/jama.281.17.1623

[8] MINSKY BD, PAJAK TF, GINSBERG RJ, PISANSKY TM, MARTENSON J, et al. INT 0123 (Radiation Therapy Oncology Group 94-05) phase III trial of combined-modality therapy 
for esophageal cancer: high-dose versus standard-dose radiation therapy. J Clin Oncol 2002; 20: 1167-1174. http://dx.doi. org/10.1200/JCO.20.5.1167

[9] YAMASHITA H, OKUMA K, WAKUI R, KOBAYASHISHIBATA S, OHTOMO K, et al. Details of recurrence sites after elective nodal irradiation (ENI) using 3D-conformal radiotherapy (3D-CRT) combined with chemotherapy for thoracic esophageal squamous cell carcinoma--a retrospective analysis. Radiother Oncol 2011; 98: 255-260. http://dx.doi. org/10.1016/j.radonc.2010.10.021

[10] CHANDRA A, GUERRERO TM, LIU HH, TUCKER SL, LIAO Z, et al. Feasibility of using intensity-modulated radiotherapy to improve lung sparing in treatment planning for distal esophageal cancer. Radiother Oncol 2005; 77: 247-253. http://dx.doi.org/10.1016/j.radonc.2005.10.017

[11] FENKELL L, KAMINSKY I, BREEN S, HUANG S, VAN PROOIJEN M, et al. Dosimetric comparison of IMRT vs. $3 \mathrm{D}$ conformal radiotherapy in the treatment of cancer of the cervical esophagus. Radiother Oncol 2008; 89: 287-291. http://dx.doi.org/10.1016/j.radonc.2008.08.008

[12] ODRAZKA K, PETERA J, ZOUHAR M, VOSMIK M, VACULIKOVA $\mathrm{M}$, et al. Clinical results of intensity-modulated radiation therapy (IMRT) for tumors of the head and neck region. Neoplasma 2005; 52: 85-94.

[13] NISHIMURA Y, MITSUMORI M, HIRAOKA M, KOIKE $\mathrm{R}$, NAKAMATSU K, et al. A randomized phase II study of cisplatin/5-FU concurrent chemoradiotherapy for esophageal cancer: Short-term infusion versus protracted infusion chemotherapy (KROSG0101/JROSG021). Radiother Oncol 2009; 92: 260-265. http://dx.doi.org/10.1016/j.radonc.2008.12.012

[14] VAN HAGEN P, HULSHOF MC, VAN LANSCHOT JJ, STEYERBERG EW, VAN BERGE HENEGOUWEN MI, et al. Preoperative chemoradiotherapy for esophageal or junctional cancer. N Engl J Med 2012; 366: 2074-2084. http://dx.doi. org/10.1056/NEJMoa1112088

[15] ZHAO KL, HU XC, WU XH, FU XL, FAN M, et al. A phase I dose escalation study of Nimotuzumab in combination with concurrent chemoradiation for patients with locally advanced squamous cell carcinoma of esophagus. Invest New Drugs 2012; 30: 1585-1590. http://dx.doi.org/10.1007/s10637-011-9735-0

[16] BUTTON MR, MORGAN CA, CROYDON ES, ROBERTS SA Crosby TD. Study to determine adequate margins in radiotherapy planning for esophageal carcinoma by detailing patterns of recurrence after definitive chemoradiotherapy. Int J Radiat Oncol Biol Phys 2009; 73: 818-823. http://dx.doi. org/10.1016/j.ijrobp.2008.04.062
[17] SAKAI M, SUZUKI S, SANO A, TANAKA N, INOSE T, et al. Significance of lymph node capsular invasion in esophageal squamous cell carcinoma. Ann Surg Oncol 2012; 19: 1911-1917. http://dx.doi.org/10.1245/s10434-012-2232-7

[18] D'JOURNO XB, AVARO JP, MICHELET P, TROUSSE D, TASEI AM, et al. Extracapsular lymph node involvement is a negative prognostic factor after neoadjuvant chemoradiotherapy in locally advanced esophageal cancer. J Thorac Oncol 2009; 4: 534-539. http://dx.doi.org/10.1097/ JTO.0b013e31819c862d

[19] METZGER R, DREBBER U, BALDUS SE, MONIG SP, HOLSCHER AH, et al. Extracapsular lymph node involvement differs between squamous cell and adenocarcinoma of the esophagus. Ann Surg Oncol 2009; 16: 447-453. http://dx.doi. org/10.1245/s10434-008-0248-9

[20] APISARNTHANARAX S, ELLIOTT DD, EL-NAGGAR AK, ASPER JA, BLANCO A, et al. Determining optimal clinical target volume margins in head-and-neck cancer based on microscopic extracapsular extension of metastatic neck nodes. Int J Radiat Oncol Biol Phys 2006; 64: 678-683. http://dx.doi. org/10.1016/j.ijrobp.2005.08.020

[21] YUAN S, MENG X, YU J, MU D, CHAO KS, et al. Determining optimal clinical target volume margins on the basis of microscopic extracapsular extension of metastatic nodes in patients with non-small-cell lung cancer. Int J Radiat Oncol Biol Phys 2007; 67: 727-734. http://dx.doi.org/10.1016/ j.ijrobp.2006.08.057

[22] GHADJARP, SCHREIBER-FACKLAM H, GRATER R, EVERS C, SIMCOCK M, et al. Quantitative analysis of extracapsular extension of metastatic lymph nodes and its significance in radiotherapy planning in head and neck squamous cell carcinoma. Int J Radiat Oncol Biol Phys 2010; 76: 1127-1132. http://dx.doi.org/10.1016/j.ijrobp.2009.03.065

[23] EDGE SB American Joint Committee on Cancer. AJCC cancer staging manual. New York: Springer, 2010.

[24] BABA M, AIKOU T, NATSUGOE S, KUSANO C, SHIMADA $\mathrm{M}$, et al. Lymph node and perinodal tissue tumor involvement in patients with esophagectomy and three-field lymphadenectomy for carcinoma of the esophagus. J Surg Oncol 1997; 64: 12-16. http://dx.doi.org/10.1002/(SICI)10969098(199701)64:1<12::AID-JSO3>3.0.CO;2-S

[25] TANABE T, KANDA T, KOSUGI S, IKEDA Y, MAKINO $S$, et al. Extranodal spreading of esophageal squamous cell carcinoma: clinicopathological characteristics and prognostic impact. World J Surg 2007; 31: 2192-2198. http://dx.doi. org/10.1007/s00268-007-9204-2 